Paul Courget est né en Dordogne en 1918. C'est un poète d'inspiration pluraliste avec une tendance / dominance à aborder des sujets traitant de la Nature et de l'Amour. C'est ce dernier thème qui semble convenir le mieux à sa nature profonde.

Son art poétique, nourri aux grandes écoles de la seconde moitié du dix-neuvième siècle et de la première moitié du vingtième, n'est fermé à aucune forme expressive... Il est toutefois, pour ce qui le regarde personnellement, orienté surtout vers une prosodie d'allure traditionnelle, belle, flexible, harmonieuse et sensible.

Paul Courget a publié une vingtaine de recueils, participé à une soixantaine d'anthologies et recueils collectifs et collaboré à de nombreux journaux et périodiques.

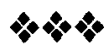

\title{
Le Don
}

Voici qu'en ces instants où la raison chavire,

Nos corps, obéissant à l'ancestral désir,

Ont, énivrês d'amour, de joie et de plaisir,

Confondu les émois de leur vibrant délire.

Ils étaint l'un pour l'autre, hier, des inconnus Poursuivant sans écho leur chemin solitaire.

Par quel obscur dessein de Dieu, par quel mystère,

Se sont-ils retrouvés unis, fiévreux et nus?

Leur a-t-il donc suffi de céder au miracle

D'un échange surpris de regards caressants,

Pour aussitôt répondre à l'ardent veau des sens

Et dans un don total le porter au pinacle?

Victimes des effets de ce mal tout puissant

Venu broyer les coeurs depuis les premiers âges,

Ils ont, d'un même élan, révélant les prësages

D'un sûr destin, mêlé la sève de leur sang. 
Ils n'éluderont pas la fatale attirance Qui les fit, ici bas, intimement s'aimer. Et se satisferont du bonheur d'assumer Sans percer son secret, l'adorable souffrance...

Ils auront dérobé la part d'éternité

Enclose dans l'éclair d'une vivante extase Et connu cette mort qui, suivant l'êpectase. Couronne d'infini le cri de volupté.

Rien ne subsisterait, sur la cendre future Du brasier d'où jaillit leur éblouissement, Si ne les ranimaient encor ces vers d'amant Pour sauver de l'oubli l'édénique aventure! 